\title{
The Effect of the Accounting and Business Curriculums on Creativity
}

\author{
Ya-Yun Cheng ${ }^{1, *}$, Chin-Chen Chien $^{2} \&$ Shiow-Jen Wang ${ }^{2}$ \\ ${ }^{1}$ Department of Applied Finance, HsiuPing University of Science and Technology, Taichung City, Taiwan, R.O.C. \\ ${ }^{2}$ Department of Accountancy, National Cheng Kung University, Tainan City, Taiwan, R.O.C. \\ *Correspondence: Department of Applied Finance, HsiuPing University of Science and Technology, Taichung City, \\ Taiwan, R.O.C. No.11 Gongye Rd, Dali Dist., Taichung City 41280,Taiwan, R.O.C. Tel: 886-4-24961123ext.2407. \\ E-mail: yycheng@hust.edu.tw
}

Received: November 4, 2016

doi:10.5430/jct.v5n2p127
Accepted: November 14, 2016 Online Published: November 26, 2016

URL: http://dx.doi.org/10.5430/jct.v5n2p127

\begin{abstract}
This study employs the Torrance Tests of Creative Thinking to investigate the effects of accounting and business curriculums on students' verbal and figurative creativity via the Solomon four-group design. The subjects are accounting and business administration students in Taiwan, where these two curriculums are similar to their counterparts in the U.S.A. The test scores were analyzed with MANOVA and meta-analysis. The results show that the accounting curriculum has not been as effective as the business administration curriculum with respect to both verbal and figurative creativity. These results indicate that in today's dynamic and competitive business environment, the accounting curriculum needs to be redesigned in a variety of aspects regarding creative thinking and problem solving to meet the challenge.
\end{abstract}

Keywords: accounting education; verbal creativity; figurative creativity; accounting curriculum

\section{Introduction}

For more than a decade, leaders in the accounting profession have raised great concerns regarding the problems of traditional accounting education. Earlier studies suggested that accountants are fluent in numbers adhere to the details but lack creativity (Bougen, 1994; Albrecht \& Sack, 2000; Carnegie \& Napier, 2010; Bryant, Stone, \& Wier, 2011). They also suggested that an accounting education and work experience might eradicate accountants' creativity in order to facilitate the rule-based, algorithmic method to accounting work (Albrecht \& Sack, 2000; Bryant et al., 2011). Moreover, Albrecht and Sack (2000) have found that accounting students generally lack the skills to analyze, judge and communicate clearly. They also mention that accounting curriculums need an overhaul to move students beyond narrowly focused content and technical training to educational activities that develop capacities for creative thinking and problem solving. Their views have been shared by the Institute of Chartered Accountants in Australia (2010)(Note 1), as well as many individual researchers, such as Jones and Davidson (2007), Springer and Borthick (2004), and Kealey (2005).

In response to these repeated pleas for the reform of accounting curriculums, we specifically addressed the issue of this program on students' creative thinking. Creative thinking refers to how people approach problems and provides solutions along with their capacity to put existing ideas together in new combinations. Amabile $(1998$, p. 78$)$ states that "The creativity within each of us is a function of three components: expertise, creative-thinking skills, and motivation." It is by and large agreed that creative thinking is one of the most valuable human resources. The evolution of modern accounting theory and practice would be hindered if creativity is not rigorously exercised. For instance, the emergence of double-entry accounting would be impossible without creativity.

Some people are most likely to be preoccupied with financial accounting, managerial accounting and auditing as they play equivalent roles in this profession. The renowned DuPont Formula provides General Motors with the grounds for evaluation of the division's performance, which makes decentralization possible. It also provides financial analysts with important indicators for investment decision making. The breakdown of cost into fixed and variable components allows managers to decide whether the product should be internally produced or externally purchased. The relatively developed activity-based accounting and strategic cost management are both ingenious ideas that could only be contrived by creative individuals, and their impact on modern business has been profound. 
However, we have to be cautious of misconceiving creative thinking within accounting as 'creative accounting', which has recently had a dubious reputation for corporate scandals. Creative accounting is a process whereby the accountants use their knowledge of accounting rules to manipulate the figures reported in the accounts of a business in order to create a different view of its performance. There is a tendancy to fear these creative accounting methods; meanwhile, most research holds ethical issues about this practice (Jennings, 2004; Gowthorpe \& Amat, 2005). Alternatively, CPAs, who have been largely exposed to a rule-based environment in their career lack the "creative capability" to disprove the myth of the "creative business model" developed by non-accountants. This is evidenced by the frequent audit failures with respect to off-balance-financing and hedge accounting that employ either very sophisticated business models or complicated financial derivatives.

To address the issue, we employed a new creativity test (Wu, et al., 1988) referred to the Torrance Tests of Creative Thinking (TTCT) to measure the subjects' verbal and figurative creativity, and the Solomon four-group design to assess the effect of the accounting curriculum on these two creativity indices. The subjects are accounting students and business administration students in Taiwan. The majority of the faculty members (more than ninety percent) of these two departments have the highest degree in their field from either the United States of America (U.S.A.) or the United Kingdom (U.K.), and the textbooks are all written in English. Essentially, the curriculum is comparable to their counterparts in the U.S.A.

To ensure the external validity of this study, we conducted a pretest at the time when these students were enrolled in university. Accounting and business freshmen were assigned to the experimental and control group, respectively. We performed the posttest on the senior students to safeguard the pretest effect. However, the most important experimental design is a follow-up test three years later when the freshmen were seniors. This experimental design allows us to assess the effect of these two curriculums on creativity. We analyzed the data with the employment of MANOVA and meta-analysis. The results show that although the accounting students had outperformed their counterparts in both verbal and figurative creativity when they were enrolled as freshmen, they lost the merits to business students after having been immersed in the accounting curriculum for three years.

The paper is organized as follows. The second section outlines the background and hypotheses. The third section details the research procedures. The fourth section presents and analyzes experimental results. The last section concludes the study with suggestions for refining accounting education.

\section{Background and Hypotheses}

It is generally agreed that a modern-day accounting professional should possess strong communication skills and creativity(Note 2). For example, Shalley, Zhou, and Oldham (2004) suggest that creativity is essential for problem solving and is a precursor to innovation. Bryant et al. (2011) found that professional accounting work requires no less creativity than do three competing professions such as Law, Engineering, and Health Care. Schlee and Harich (2014) propose that creativity has been viewed as a critical component for business education, and should be included in all business programs.

Nevertheless, the cultivation of these qualities is closely interrelated with the content and method of an accounting education. Porter and Mckibbin (1998) argue that a traditional accounting education is so narrow in scope that students are taught nothing but accounting. They lack the skills to analyze, judge and communicate. Donelan and Reed (1992) suggest that skills possessed by accounting professionals should include not only accounting knowledge, but also creativity in order to cope with the ever-changing financial environment.

Torrance $(1962,1966, \& 1974)$ sees creativity as a process and therefore developed battery tests. Creative thinking can be present in a problem solving process that involves divergent and convergent thinking. Divergent thinking is the ability to consciously generate new ideas that branch out to many possible solutions for a given problem. Divergent-thinking tests thus require individuals to produce several responses to a specific prompt, in contrast to a single correct one. This is contrary to convergent thinking, which is measured by IQ tests and involves solving well-defined rational problems that have one correct answer. Thus, a traditional accounting education is within the domain of convergent thinking.

The knowledge of a domain does not always lead to creativity. Some investigators have argued that very high levels of domain-specific knowledge can, in some instances, work against creativity (Nickerson, 1999). Csikszentmihalyi (1996) concluded that a person who wants to make a creative contribution not only must work within a creative system, but must also reproduce that system within his or her own mind. The idea is that experts in an area can become so committed to a standard or 'correct' way of approaching problems in their area of expertise that they are 
unlikely to consider the possibility of alternative approaches (Frensch \& Sternberg, 1989; Simonton, 1984). Thus, it is interesting to investigate whether the traditional accounting curriculum that focuses on the rule-based training impairs students' creativity.

According to Csikszentmihalyi's creativity model (1996), for creativity to occur, a set of rules and practices must be transmitted from the domain to the individual. The individual must produce a novel variation in the content of the domain, and the variation must then be selected by the field for inclusion in the domain. Several aspects are noteworthy about this view of creativity in relation to higher education. First, creativity is not an abstract property or talent that only some individuals possess (Policastro \& Gardner, 1999). If creativity resides not in the individual, but in the relationship between the individual and the domain, it may be possible to enhance the individual's creative performance through appropriate interactions with the domain and the field (Lovitts, 2005). Second, experts who recognize and agree that an innovation is worthy of inclusion in the domain will serve as gatekeepers. In order for such experts to agree on the value of an innovation, they must possess a similar set of internal standards for their judgements. Similar to these experts, the higher education faculty exist as the gatekeepers in the domain. If the higher education faculty's implicit standards for their judgments are made explicit, they could be used to help guide students to higher levels of performance (Johnston, 1997; Tinkler \& Jackson, 2000; Winter, Griffiths, \& Green, 2000; Mullins \& Kiley, 2002).

The content and delivery method in accounting education therefore fits this description (Karr, 2002). The educational model also feeds into the hiring practices, where college graduates with degrees in accounting apprentice at public accounting firms before deciding whether to continue to work as generalists or specialize taxation or auditing.

Driver (2001) describes ways of fostering creative behaviors that include allowing mistakes and offering free rather than restricted choices. The Accounting field operates within the realm of rule-based standards such as the Financial Accounting Standards, or the principle based standards such as International Accounting Standards. Nevertheless, both are focused, disciplined, and constrained. They lead to conservative, not creative thinking. Thus, conservative thinking requires adherences to existing rules (Sternberg, 1997), while creative thinking refers to analyzing, conceptualizing, reasoning, and evaluating (Thompson \& Washington, 2015).

These earlier studies and aforementioned analyses provide us with the basis to explore whether an accounting and business education convey different objects and tenets in the economic environment, which then go on to affect students' creativity in different ways.

\section{Research Method}

We employed a new test referred to as the Torrance standardized Tests of Creative Thinking $(1962,1966, \& 1974)$ to investigate this issue. The Torrance Tests of Creative Thinking (TTCT) is the most widely used (Colangelo \& Davis, 1997) and the most referenced of all creativity tests (Lissitz \& Willhoft, 1985; Kim, 2006 \& 2011; Almeida, Prieto, Ferrando, Oliveira, \& Ferrándiz, 2008; Krumm, Lemos, \& Filippetti, 2014). It is based on Guilford's hypothesis (Guilford, 1967), and measures the divergent thinking factors of fluency, flexibility, elaboration and originality. These test responses are then scored on four components: (1) Fluency-number of responses; (2) Flexibility-the degree of difference of the responses; (3) Elaboration-the amount of detail in the response, and (4) Originality-statistical infrequency of the response. The research instrument is a new creativity test referred to as Torrance's Thinking Creatively. Based on previous research, the instrument is a new creativity test for use with students in Taiwan, which originated from the TTCT and was developed by Wu et al. (1998), "The New Creativity Test" model.

The subjects who participated in this study were undergraduate accounting and business students. We could not randomly assign the students to the experimental group as those who would take the accounting curriculum, and the control group as those who would take a non-accounting curriculum, we therefore employed a quasi-experimental research design as suggested by Kerlinger and Lee (2000). This idea suggests using similar samples when random assignments are not available. Accordingly, we chose business students as the control group because the subjects are intellectually equivalent according to their scores of the uniformed university entrance examination in Taiwan.

Each of TTCT-Verbal and TTCT-Figural has two forms (Form A and Form B). We employ TTCT-Verbal and TTCT-Figural to test the subjects' ability of "Thinking Creatively with Words" and "Thinking Creatively with Pictures", respectively. The verbal TTCT measures three mental characteristics: fluency, flexibility and originality, while the figurative TTCT assesses four divergent reasoning factors of the subjects: fluency, flexibility, originality and elaboration. Fluency is determined by the sheer quantity of responses; flexibility, by the number of different 
categories of responses; originality, by the uniqueness of the response (relative to a set of responses); and elaboration, by the details given in the response.

We utilize the Solomon (1949) design due to its robustness recommended in previous research. As shown in Figure 1, the Solomon design has one experimental group and three control groups. Campbell and Stanley (1963) suggested that this design can effectively maintain internal validity because it controls the problems arising from pretest-posttest, history, and maturation during the experimental procedure. The presence of pretest sensitization prevents generalization of results from the pretested sample to an unpretested population (Bracht \& Glass, 1968; Huck \& Sandler, 1973). The Solomon design expands this pretest-posttest design with two additional control groups (the senior accounting and business students for only the posttest) that did not take the pretest to enhance the internal validity. Moreover, this design allows us to control the contemporaneous effects between pretest scores and posttest scores, and to eliminate the measurement errors through repeated experiments. The Solomon design can also control the selection bias via the following four experimental comparisons: (1) $Y_{1 a}$ vs. $Y_{1 b}$, (2) $Y_{1 a}$ vs. $Y_{2 a}$ (3) $Y_{1 c}$ vs. $Y_{2 c}$ and $Y_{1 c}$ vs. $Y_{2 b}$. Thus, the experimental results will be robust because of these four repeated comparisons in addition to the interactive effect test.

\begin{tabular}{cccc}
\hline$Y_{1 b}$ & $X$ & $Y_{1 a}$ & $\begin{array}{c}\text { Experimental } \\
\text { (Accounting majors with pretest) }\end{array}$ \\
\hline$Y_{2 b}$ & $\sim X$ & $Y_{2 a}$ & Control 1 \\
& $X$ & $Y_{1 c}$ & (Business Administration majors with pretest) \\
& & Control 2 \\
& & $Y_{2 c}$ & (Accounting majors, posttest only) \\
& & Control 3 \\
\end{tabular}

Figure 1. Solomon Design

Notes:

(1) $\mathrm{X}$ is the main factor (DEP) used to define an experimentally manipulated independent variable. This is Accounting training (ACC) in our research.

(2) Y: dependent variable from creativity test scores.

(3) The line between the different levels indicates separate groups.

(4) $\sim \mathrm{X}$ : not $\mathrm{X}$ in our research is Business Administration Department training (BA).

(5) Experiment Group: Accounting majors with the pretest (ACC DEP* Pretest)

Control 1 Group: Non-Accounting majors with the pretest (BA DEP* Pretest)

Control 2 Group: Accounting majors without the pretest (ACC DEP* Posttest only)

Control 3 Group: Non-Accounting majors without the pretest (BA DEP* Posttest only)

We conducted the pretests for both the freshman accounting and business students during the first few sessions of the semester after they had been enrolled into the program. $Y_{1 b}$ and $Y_{2 b}$ represent their TTCT pretest scores, respectively. Meanwhile, the senior accounting and business students served as control groups 2 and 3, respectively, and $Y_{1 c}$ and $Y_{2 c}$ denote their TTCT creativity scores. We conducted the posttests with the same subjects three years later when they were seniors, and $Y_{1 a}$ and $Y_{2 a}$ represent their TTCT posttest creativity scores. It is worth noting that both programs are very competitive at the university level. By and large, less than one percent of the students in these two departments chose to change their majors. In addition, the quota set by the Ministry of Education allowed only five students to transfer from other departments to either accounting or business, and only one or two students dropped out from these two departments. In sum, the students' profiles are constant throughout our study.

Although the potential weakness of quantitative methods is the intrusive nature of testing in general, and pretesting specifically, the Solomon four-group design can be utilized to ameliorate this difficulty by a $2 \times 2$ analysis of variance (ANOVA) as Figure 2. 


\begin{tabular}{|c|c|c|c|}
\hline $\begin{array}{c}\text { Factors and treatment } \\
\text { levels }\end{array}$ & $\begin{array}{l}\text { PRETEST }_{a} \\
\text { (With Pretest) }\end{array}$ & $\begin{array}{c}\text { PRETEST }{ }_{c} \\
\text { (Without Pretest) }\end{array}$ & Row means \\
\hline $\begin{array}{c}\mathrm{DEP}_{1} \\
\text { (ACC DEP.) }\end{array}$ & $Y_{1 a}$ & $Y_{1 c}$ & $\overline{Y_{1 . .}}$ \\
\hline $\begin{array}{c}\mathrm{DEP}_{2} \\
\text { (BA DEP.) }\end{array}$ & $Y_{2 a}$ & $Y_{2 c}$ & $\overline{Y_{2 . \bullet}}$ \\
\hline Column means & $\overline{Y_{\text {ou }}}$ & $\overline{Y_{\bullet \bullet}}$ & $Y_{\ldots}$ \\
\hline
\end{tabular}

Figure 2. Solomon Design Statistical test, $2 \times 2$ Factorial Analysis of Variance

Notes:

(1) DEP is used to define an experimentally manipulated independent variable, the treatment level DEP ${ }_{1}$ is Accounting Department training ACC in our research, $\mathrm{DEP}_{2}$ is a separate treatment level, and BA is Business Administration Department training.

(2) $T$ is defined by the other factor, PRETEST and the treatment levels, PRETEST ${ }_{a}$, PRETEST $_{c}$ denotes subjects with and without pretests respectively.

(3) $\mathrm{Y}$ is a dependent variable with creativity test scores.

(4) $Y_{1 a}$ is a posttest response of senior accounting students.

$Y_{2 a}$ is a posttest response of senior business administration students.

$Y_{1 c}$ is a response of senior accounting students without a pretest.

$Y_{2 c}$ is a response of senior business administration students without a pretest.

However, the Solomon four-group design is somewhat complicated. In order to simplify the complicated research designs, we adopted Braver and Braver (1988) who used a meta-analytic technique as shown in Figure 3. The flowchart details the statistical tests and their sequence in analyzing the Solomon four-group

design. The flowchart begins with a $2 \times 2$ analysis of variance (ANOVA) on the means of $Y_{1 a}, Y_{2 a}, Y_{1 c}, Y_{2 c}$, which examines the interaction of the PRETEST factor on the DEP factor. Pretest sensitization is indicated if this test is statistically significant. A statistically significant interaction should be followed up with a simple effects test on the means of the pretested groups $\left(Y_{1 a}, Y_{2 a}\right)$, and a simple effects test on the means of the unpretested groups ( $\left.Y_{1 c}, Y_{2 c}\right)$. If the interaction effect in the $2 \times 2$ ANOVA is not statistically significant, the analysis continues with a test of the main effects for the experimental versus control group.

Conditioned on these preliminary tests not being statistically significant, the process continues with an analysis of covariance (ANCOVA) on $Y_{1 a}, Y_{2 a}$, with $Y_{1 b}, Y_{2 b}$ as a covariate. If the ANCOVA is not statistically significant, a t-test is conducted on $Y_{1 c}$ and $Y_{2 c}$. The t-test should not be statistically significant, and the final step is to conduct a meta-analysis.

As specified in Figure 3, we first perform two $2 \times 2$ MANOVA on both Verbal Creativity scores and Figurative Creativity scores. MANOVA tests, whether there are differences between groups in a combination of Verbal (Figurative) subscores, can be attributed to the effect of the accounting curriculum. The MANOVA model is:

$$
Y_{i j k}=\mu_{. .}+\alpha_{i}+\tau_{j}+(\alpha \tau)_{i j}+\varepsilon_{i j k}
$$

where

$\mu_{\text {.. }}$ represents an overall level;

$\alpha_{i}$ represents the main effect of DEP factor treatment $i ; i=1$ if the subject is an accounting (ACC) major, and $i=2$ if the subject is a (BA) major;

$k=1 \ldots . n_{i j}$;

$\tau_{j}$ is the main effect of the PRETEST factor treatment $j ; j=a$ if the subject participated in a pretest, $j=c$ if the subject did not;

$(\alpha \tau)_{i j}$ is the interaction between the DEP factor and the PRETEST; 
$Y_{i j k}$ is the vector response consisting of several components of creativity scores;

$\varepsilon_{i j k}$ is the error term.

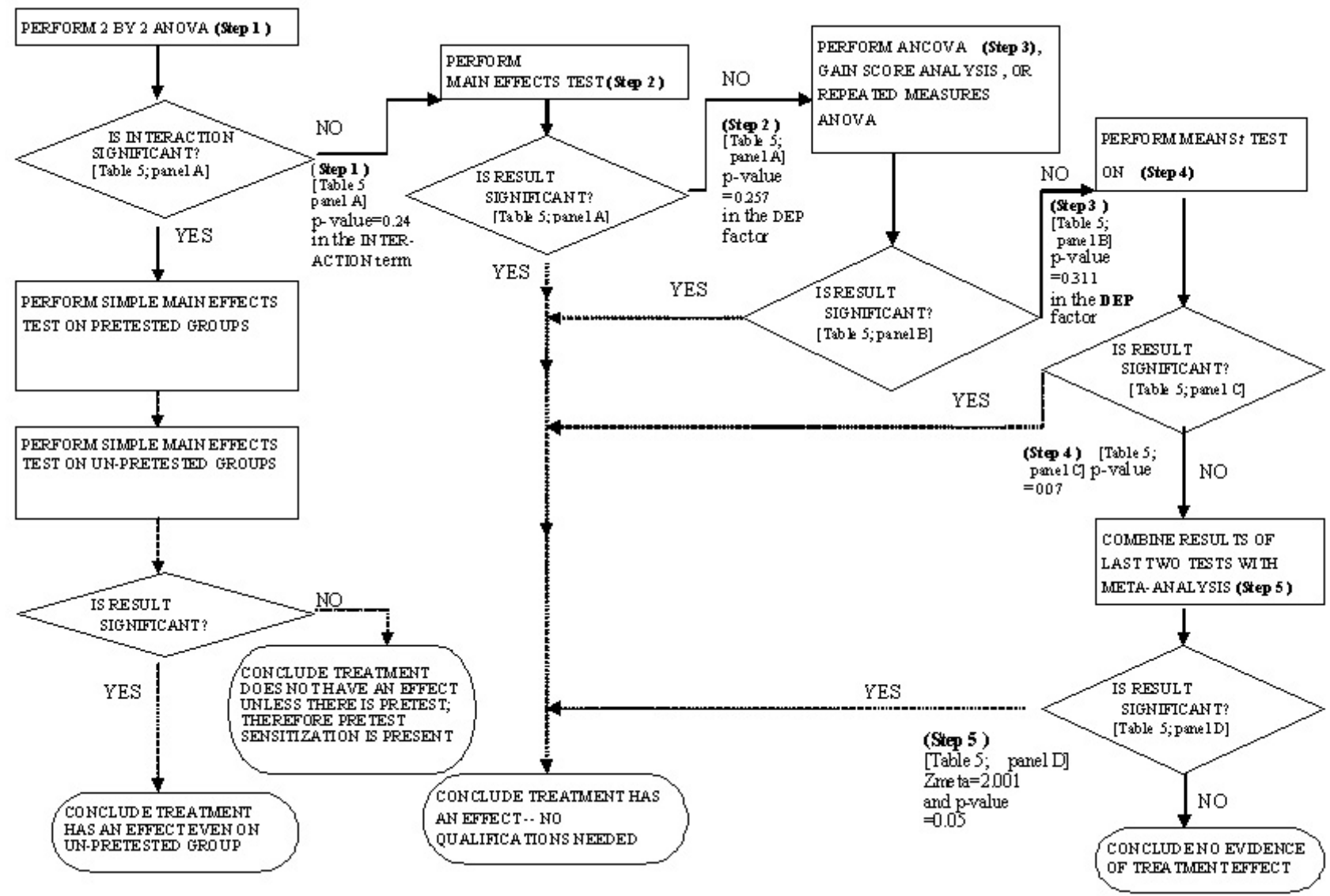

Figure 3. Flowchart of Tests and Conclusions (Braver \& Braver, 1988)

The MANOVA procedures for the first test produce the following null hypothesis:

$H_{0}$ : for all $(\alpha \tau)_{i j}=0$, where $i=1$ if the subject is an accounting major (ACC), $i=2$ if the subject is a business administration major (BA) $j=a$ if the subject participated in a pretest and $j=c$ if the subject did not. We aim to test whether or not there is any interactive effect of the PRETEST factor on the DEP factor in the first place to examine the pretest sensitization. The test statistic is Wilks' $\lambda$ (Wilks, 1932) and $H_{0}$ will be rejected for small $\lambda$ values. The rejection of the null hypothesis indicates that there is an interactive effect between the major effect and the pretest effect, which will make the interpretation of the results more complicated.

In other words, only if the null hypothesis cannot be rejected will we proceed to test the main effects of the pretest treatment and curriculum treatment with the following null hypotheses:

$$
\begin{aligned}
& H_{0}: \tau_{\mathrm{a}}=\tau_{c}=0 \text {; and } \\
& H_{0}: \alpha_{1}=\alpha_{2}=0
\end{aligned}
$$

There exists the pretest effect if the null hypothesis, $H_{0}: \tau_{\mathrm{a}}=\tau_{c}=0$ is rejected. Under this circumstance, some post-hoc tests from group differences should be used to determine how the ACC group mean differs significantly from the BA group. However, our ultimate goal is to test whether or not the null hypothesis of the curriculum treatment $\left(H_{0}: \alpha_{1}=\alpha_{2}=0\right.$ ) can be rejected, which suggests that the accounting curriculum has a significant impact on students' verbal and/or figurative creativity. 


\section{Empirical Results and Discussions}

Table 1 summarizes the descriptive statistics of the test scores for each subgroup. The alpha values used to measure internal consistence are reasonably high with most being greater than 0.8 .

Table 1. Descriptive Statistics of Test Scores

\begin{tabular}{|c|c|c|c|c|c|c|c|c|c|}
\hline \multirow{2}{*}{ Group } & \multirow{2}{*}{\multicolumn{2}{|c|}{ Department }} & \multicolumn{3}{|c|}{ Verbal } & \multicolumn{4}{|c|}{ Figurative } \\
\hline & & & FLU & FLEX & ORIG & FLU & FLEX & ORIG & ELAB \\
\hline \multirow{6}{*}{ Pre-testing } & $\mathrm{ACC}$ & Mean & 11.07 & 7.63 & 6.83 & 12.44 & 8.45 & 7.87 & 5.63 \\
\hline & $\left(Y_{1 b}\right)$ & $(S D)$ & $(4.80)$ & (2.39) & $(4.83)$ & $(5.13)$ & $(3.08)$ & $(4.87)$ & $(2.87)$ \\
\hline & $\mathrm{N}=46$ & Alpha & 0.73 & 0.72 & 0.78 & 0.72 & 0.73 & 0.70 & 0.74 \\
\hline & B_A & Mean & 8.30 & 6.42 & 4.39 & 14.27 & 9.21 & 8.73 & 5.67 \\
\hline & $\left(Y_{2 b}\right)$ & $(S D)$ & $(3.21)$ & $(2.36)$ & $(3.69)$ & $(5.52)$ & $(2.75)$ & (5.16) & $(3.02)$ \\
\hline & $\mathrm{N}=33$ & Alpha & 0.83 & 0.84 & 0.86 & 0.84 & 0.84 & 0.83 & 0.87 \\
\hline \multirow{6}{*}{$\begin{array}{l}\text { Post-testin } \\
\mathrm{g}\end{array}$} & ACC & Mean & 13.00 & 7.85 & 10.80 & 15.58 & 10.74 & 12.94 & 2.41 \\
\hline & $\left(Y_{1 a}\right)$ & $(S D)$ & $(5.83)$ & (2.62) & (16.20) & $(5.27)$ & $(2.51)$ & $(2.89)$ & (2.41) \\
\hline & $\mathrm{N}=46$ & Alpha & 0.39 & 0.48 & 0.75 & 0.45 & 0.50 & 0.43 & 0.54 \\
\hline & B_A & Mean & 14.36 & 8.24 & 9.39 & 15.88 & 9.85 & 11.03 & 4.39 \\
\hline & $\left(Y_{2 a}\right)$ & $(S D)$ & $(7.84)$ & (3.08) & (7.89) & $(5.42)$ & (3.03) & $(6.37)$ & (3.38) \\
\hline & $\mathrm{N}=33$ & Alpha & 0.75 & 0.79 & 0.80 & 0.77 & 0.80 & 0.80 & 0.83 \\
\hline \multirow{6}{*}{$\begin{array}{l}\text { Post-testin } \\
\text { g only }\end{array}$} & $\mathrm{ACC}$ & Mean & 10.26 & 7.23 & 6.58 & 12.88 & 8.89 & 9.42 & 3.28 \\
\hline & $\left(Y_{1 c}\right)$ & $(S D)$ & $(4.88)$ & (3.09) & $(4.52)$ & $(5.23)$ & (3.19) & $(5.92)$ & $(2.74)$ \\
\hline & $\mathrm{N}=57$ & Alpha & 0.83 & 0.84 & 0.84 & 0.82 & 0.83 & 0.85 & 0.87 \\
\hline & B_A & Mean & 13.43 & 8.62 & 8.45 & 13.91 & 9.25 & 9.60 & 4.21 \\
\hline & $\left(Y_{2 c}\right)$ & $(S D)$ & $(6.37)$ & $(2.79)$ & $(5.54)$ & $(5.89)$ & $(3.04)$ & $(7.23)$ & $(4.37)$ \\
\hline & $\mathrm{N}=53$ & Alpha & 0.88 & 0.90 & 0.88 & 0.88 & 0.90 & 0.89 & 0.90 \\
\hline
\end{tabular}

Notes: The specification of notations: FLU is fluency; FLEX is flexibility; ORIG is originality and ELAB is elaboration. Alpha is the Cronbach's alpha. $Y_{1 b}$ is the subsample of freshmen with ACC majors who nerform the TTCT pretest. $Y_{2 b}$ is the subsample of freshmen with B_A majors who perform the TTCT pretest. $Y_{1 a}$ is the TTCT post test performed by the subsample of seniors with ACC majors who had performed the TTCT pretest when they were freshmen. $Y_{2 a}$ is the TTCT post test performed hy the subsample of seniors with B_A majors who had performed the TTCT pretest when they were freshmen. $Y_{1 c}$ is the TTCT post test performed by the subsample of seniors with ACC majors who had not performed the TTCT pretest when they were freshmen. $Y_{2 c}$ is the TTCT post test performed by the subsample of seniors with B_A majors who had not performed the TTCT pretest when they were freshmen.

Panel A of Table 2 shows the results of the pretest between the accounting and business students at the time when they enrolled in the programs. It indicates that the accounting students outperformed business students with respect to all three verbal creativity measures (FLU, FLEX, AND ORIG) at a five percent significance level. The t-statistics are $3.06,2.23$, and 2.85 with p-values $0.003,0.029$, and 0.066 , respectively. Although it seems that business students perform better with respect to figurative creativity measures, the difference is insignificant. The $t$-statistics for the Figurative measures, FLU, FLEX, ORIG, and ELAB, between accounting and business students are $-1.43,-0.55$, -0.75 , and -0.05 with p-values $0.16,0.58,0.46$, and 0.96 , respectively. The results rule out our concerns about the sample selection problem that accounting students are less creative than business students due to their aptitude. Contradictory to the stereotype that accounting students are likely to be more conservative and less creative, we found that accounting students had higher scores in figurative aspects than the business students during their freshmen year. 
Table 2. Two-Sample Difference of Means Test: ACC Group v.s. B_A Group

\begin{tabular}{|c|c|c|c|c|c|c|c|c|}
\hline \multicolumn{9}{|c|}{ Panel A: Pre-testing scores } \\
\hline \multirow{2}{*}{ Department } & & \multicolumn{3}{|c|}{ Verbal } & \multicolumn{4}{|c|}{ Figurative } \\
\hline & & FLU & FLEX & ORIG & FLU & FLEX & ORIG & ELAB \\
\hline $\mathrm{ACC}$ & Mean & 11.07 & 7.63 & 6.83 & 12.44 & 8.45 & 7.87 & 5.63 \\
\hline$\left(Y_{1 b}{ }^{\mathrm{a}}\right)$ & $(S D)$ & $(5.83)$ & $(2.39)$ & $(4.83)$ & $(5.13)$ & $(3.08)$ & $(4.87)$ & $(2.87)$ \\
\hline \multicolumn{9}{|l|}{$\mathrm{N}=46$} \\
\hline B_A & Mean & 8.30 & 6.42 & 4.39 & 14.27 & 9.21 & 8.73 & 5.67 \\
\hline$\left(Y_{2 b}{ }^{\mathrm{b}}\right)$ & $(S D)$ & $(3.21)$ & $(2.36)$ & (3.69) & $(5.52)$ & $(2.75)$ & $(5.16)$ & $(3.02)$ \\
\hline \multicolumn{9}{|l|}{$\mathrm{N}=33$} \\
\hline Diff & $t$ & 3.06 & 2.23 & 2.85 & -1.43 & -0.55 & -0.75 & -0.05 \\
\hline$\left(Y_{1 b}-Y_{2 b}\right)$ & p-value & 0.003 & 0.029 & 0.006 & 0.16 & 0.58 & 0.46 & 0.96 \\
\hline \multicolumn{9}{|c|}{ Panel B: Post-testing scores } \\
\hline \multirow{2}{*}{ Department } & & \multicolumn{3}{|c|}{ Verbal } & \multicolumn{4}{|c|}{ Figurative } \\
\hline & & FLU & FLEX & ORIG & FLU & FLEX & ORIG & ELAB \\
\hline $\mathrm{ACC}$ & Mean & 13.00 & 7.85 & 10.80 & 15.58 & 10.74 & 12.94 & 2.41 \\
\hline$\left(Y_{1 a}{ }^{\mathrm{c}}\right)$ & $(S D)$ & $(5.83)$ & $(2.62)$ & $(16.20)$ & $(5.27)$ & $(2.51)$ & $(2.89)$ & $(2.41)$ \\
\hline \multicolumn{9}{|l|}{$\mathrm{N}=46$} \\
\hline B_A & Mean & 14.36 & 8.24 & 9.39 & 15.88 & 9.85 & 11.03 & 4.39 \\
\hline$\left(Y_{2 a}{ }^{\mathrm{d}}\right)$ & $(S D)$ & $(7.84)$ & $(3.08)$ & $(7.89)$ & $(5.42)$ & $(3.03)$ & $(6.37)$ & $(3.38)$ \\
\hline \multicolumn{9}{|l|}{$\mathrm{N}=33$} \\
\hline Diff & $t$ & -0.85 & -0.60 & 0.51 & 0.08 & 1.38 & 1.27 & -2.88 \\
\hline$\left(Y_{1 a}-Y_{2 a}\right)$ & p-value & 0.40 & 0.55 & 0.61 & 0.93 & 0.17 & 0.21 & 0.06 \\
\hline
\end{tabular}

Notes:

FLU: fluency; FLEX: flexibility; ORIG: originality; ELAB: elaboration.

a $Y_{1 b}$ is the subsample of freshmen with ACC majors who perform the TTCT pretest.

b $Y_{2 b}$ is the subsample of freshmen with B_A majors who perform the TTCT pretest.

c $Y_{1 a}$ is the TTCT post test performed by the subsample of seniors with ACC majors who had performed the TTCT pretest when they were freshmen.

d $Y_{2 a}$ is the TTCT post test performed by the subsample of seniors with B_A majors who had performed the TTCT pretest when they were freshmen.

Panel B of Table 2 presents the results of posttest between accounting and business students three years later when they were seniors. The accounting students' merit of verbal creativity over their business counterparts when they were freshmen had disappeared. The t-statistics for the Verbal measures (FLU, FLEX, and ORIG) are -0.85 , -0.60 , and 0.51 with p-values $0.40,0.55$, and 0.61 , respectively. Moreover, business students outperformed accounting students with respect to both verbal fluency and verbal flexibility in the posttest, although this was not statistically significant (the t-statistics for FLU and FLEX are -0.85 and -0.60 with p-values 0.40 and 0.55 , respectively.) Nevertheless, we also found that the discrepancies between accounting and business students with respect to three Figurative measures (FLU, FLEX, and ORIG) have also reversed. The t-statistics are 0.08, 1.38, and 1.27 with p-values $0.93,0.17$, and 0.21 , respectively. These preliminary results suggest that the accounting curriculum may have some merits in figurative creativity, but not in verbal creativity. They are generally consistent with the concerns of the leaders in accounting education regarding current accounting curriculums providing little help in improving students' communication capacity. 
Table 3. Two-Sample Difference of Means Test: Pre-Testing Group v.s. Post-Testing Group

\begin{tabular}{|c|c|c|c|c|c|c|c|c|}
\hline \multicolumn{9}{|c|}{ Panel A: Accounting Department group } \\
\hline \multirow{2}{*}{ Department } & & \multicolumn{3}{|c|}{ Verbal } & \multicolumn{4}{|c|}{ Figurative } \\
\hline & & FLU & FLEX & ORIG & FLU & FLEX & ORIG & ELAB \\
\hline ACC-post & Mean & 13.00 & 7.85 & 10.80 & 15.58 & 10.74 & 12.94 & 2.41 \\
\hline$\left(Y_{1 a}{ }^{a}\right)$ & $(S D)$ & $(5.83)$ & $(2.62)$ & $(16.20)$ & $(5.27)$ & $(2.51)$ & $(2.89)$ & $(2.41)$ \\
\hline \multicolumn{9}{|l|}{$\mathrm{N}=46$} \\
\hline ACC-pre & Mean & 11.07 & 7.63 & 6.83 & 12.44 & 8.45 & 7.87 & 5.63 \\
\hline$\left(Y_{1 b}{ }^{\mathrm{b}}\right)$ & $(S D)$ & $(5.83)$ & $(2.39)$ & $(4.83)$ & $(5.13)$ & $(3.08)$ & $(4.87)$ & $(2.87)$ \\
\hline \multicolumn{9}{|l|}{$\mathrm{N}=46$} \\
\hline Diff & $t$ & 1.74 & 0.42 & 1.60 & 3.27 & 3.23 & 4.10 & -5.82 \\
\hline$\left(\overline{Y_{1 a}}-\overline{Y_{1 b}}\right)$ & $p$-value & 0.10 & 0.68 & 0.12 & 0.002 & 0.002 & 0.001 & 0.001 \\
\hline \multicolumn{9}{|c|}{ Panel B: Business Administration Department group } \\
\hline \multirow{2}{*}{ Department } & & \multicolumn{3}{|c|}{ Verbal } & \multicolumn{4}{|c|}{ Figurative } \\
\hline & & FLU & FLEX & ORIG & FLU & FLEX & ORIG & ELAB \\
\hline B_A-post & Mean & 14.36 & 8.24 & 9.39 & 15.88 & 9.85 & 11.03 & 4.39 \\
\hline$\left(Y_{2 a}{ }^{\mathrm{c}}\right)$ & $(S D)$ & (7.84) & $(3.08)$ & (7.89) & $(5.42)$ & $(3.03)$ & $(6.37)$ & (3.38) \\
\hline \multicolumn{9}{|l|}{$\mathrm{N}=33$} \\
\hline B_A-pre & Mean & 8.30 & 6.42 & 4.39 & 14.27 & 9.21 & 8.73 & 5.67 \\
\hline$\left(Y_{2 b}{ }^{\mathrm{d}}\right)$ & $(S D)$ & $(3.21)$ & $(2.36)$ & $(3.69)$ & $(5.52)$ & $(2.75)$ & $(5.16)$ & $(3.02)$ \\
\hline \multicolumn{9}{|l|}{$\mathrm{N}=33$} \\
\hline Diff & $t$ & 4.11 & 2.69 & 3.44 & 1.14 & 0.89 & 1.61 & -1.51 \\
\hline$\left(Y_{2 a}-Y_{2 b}\right)$ & $p$-value & 0.0001 & 0.001 & 0.001 & 0.26 & 0.75 & 0.11 & 0.14 \\
\hline
\end{tabular}

Notes:

FLU: fluency; FLEX: flexibility; ORIG: originality; ELAB: elaboration.

a $Y_{1 a}$ is the TTCT post test performed by the subsample of seniors with ACC majors who had performed the TTCT pretest when they were freshmen.

b $Y_{1 b}$ is the subsample of freshmen with ACC majors who performed the TTCT pretest.

c $Y_{2 a}$ is the TTCT post test performed by the subsample of seniors with B_A majors who had performed the TTCT pretest when they were freshmen.

d $Y_{2 b}$ is the subsample of freshmen with B_A majors who performed the TTCT pretest.

The preliminary results piqued our interest to further explore why accounting students lost their merits in verbal creativity after experiencing three years of the accounting curriculum. Panel A of Table 3 shows that accounting students had not made significant improvements in verbal creativity. The test-statistics of the differences for the three Verbal measures (FLU, FLEX, and ORIG) between the pretest and posttest are 1.74, 0.42, and 1.60 with the p-values $0.10,0.68$, and 0.12 , respectively. However, Panel A also suggests that the accounting curriculum has significantly improved figurative creativity with respect to FLU, FLEX, and ORIG. The t-statistics are 3.27, 3.23, and 4.10 with the p-values $0.002,0.002$, and 0.001 , respectively.

Alternatively, Panel B shows that business students made significant improvement in verbal, but not in figurative creativity. The test-statistics of the differences for the three Verbal measures (FLU, FLEX, and ORIG) between the pretest and posttest are 4.11, 2.69, and 3.44 with the p-values $0.0001,0.001$, and 0.001 , respectively. The results also show that business students have not significantly benefited from their curriculum with respect to figurative 
creativity. This is evidenced by the t-statistics for the three Figurative measures, FLU, FLEX, and ORIG, which are 1.140 .89 , and 1.61 with the p-values $0.26,0.75$, and 0.11 , respectively.

In sum, these results suggest that the accounting/business program is more effective in improving students' figurative/verbal creativity.

Table 4 reports the results of the two control groups consisting of senior accounting and business students who did not participate in the pretest. It shows that senior business students significantly outperformed their accounting counterparts in all three verbal creativity measures, but not the figurative measures. The t-statistics for the Verbal measures are $-2.92,-2.94$, and -1.94 with the $\mathrm{p}$-values $0.004,0.01$, and 0.06 ; and the Figurative measures are -0.97 , $-0.59,-0.14$, and -1.32 with the p-values $0.34,0.56,0.89$, and 0.19 , respectively. The results are fairly consistent with Table 3.

Table 4. Two-Sample Difference of Means Test: Post-Testing Group without Pretest

\begin{tabular}{|c|c|c|c|c|c|c|c|c|c|}
\hline \multirow{2}{*}{ Group } & \multirow{2}{*}{\multicolumn{2}{|c|}{ Department }} & \multicolumn{3}{|c|}{ Verbal } & \multicolumn{4}{|c|}{ Figurative } \\
\hline & & & FLU & FLEX & ORIG & FLU & FLEX & ORIG & ELAB \\
\hline \multirow{8}{*}{$\begin{array}{c}\text { Post- } \\
\text { testing } \\
\text { without } \\
\text { pretest }\end{array}$} & $\mathrm{ACC}$ & Mean & 10.26 & 7.23 & 6.58 & 12.88 & 8.89 & 9.42 & 3.28 \\
\hline & $\left(Y_{1 c}{ }^{\mathrm{a}}\right)$ & $(S D)$ & (4.88) & (3.09) & (4.52) & (5.23) & (3.19) & $(5.92)$ & $(2.74)$ \\
\hline & $\mathrm{N}=57$ & & & & & & & & \\
\hline & B A & Mean & 13.43 & 8.62 & 8.45 & 13.91 & 9.25 & 9.60 & 4.21 \\
\hline & $\left(Y_{2 c}{ }^{\mathrm{b}}\right)$ & $(S D)$ & $(6.37)$ & $(2.79)$ & (5.54) & (5.89) & (3.04) & $(7.23)$ & (4.37) \\
\hline & $\mathrm{N}=53$ & & & & & & & & \\
\hline & Diff & $t$ & -2.92 & -2.94 & -1.94 & -0.97 & -0.59 & -0.14 & -1.32 \\
\hline & $\left(\overline{Y_{1 c}}-\overline{Y_{2 c}}\right)$ & $p$-value & 0.004 & 0.01 & 0.06 & 0.34 & 0.56 & 0.89 & 0.19 \\
\hline
\end{tabular}

Notes:

FLU: fluency; FLEX: flexibility; ORIG: originality; ELAB: elaboration.

a $Y_{1 c}$ is the TTCT post test performed by the subsample of seniors with ACC majors who had not performed the TTCT pretest when they were freshmen.

b $Y_{2 c}$ is the TTCT post test performed by the subsample of seniors with B_A majors who had not performed the TTCT pretest when they were freshmen.

We found that accounting students had higher pretest scores with respect to verbal creativity than business students, but not to figurative creativity. Generally speaking, accounting students were at least as creative as business students at the time when they were enrolled in these two departments. However, while business students have significantly improved their verbal creativity after experiencing three years of university education, accounting students stalled. On the other hand, while accounting students have significantly improved their figurative creativity, business students have only had a modest improvement.

It would be premature to jump to conclusions at this early stage because if there exists an interactive effect on the creativity between the DEP factors and the PRETEST, then the aforementioned results might be jeopardized. In fact, students who participated in the pretest during their freshman year are more apt to experiencing the interactive effects at the time when the posttest took place. For example, the results in Table 3 suggests that the post-testing scores of the four Figurative measures are all significantly greater than the pre-testing scores for accounting students at a one percent confidence level, but not vice versa for business students. In contrast, the post-testing scores of the three Verbal measures are significantly greater than pre-testing scores for business students at a one percent confidence level, but not vice versa for accounting students. The complexity of the research design is evident in Table 5, where the ANCOVA model shows that the pretesting scores have significantly affected the post-testing scores. The F statistics in Table 5 are for covariate effect tests. They are ranged between 13.77 and 55.16, and the $\mathrm{p}$-values are all less than 0.0004 . These results suggest that the covariate effect is significant. Therefore, a more complicated experimental design, such as Figure 3, should be executed to resolve statistical issues. 
Table 5. Adjusted Mean Scores and ANCOVA Results for Post-Testing Group

\begin{tabular}{|c|c|c|c|c|c|c|c|c|}
\hline \multirow{2}{*}{ Department } & \multirow{2}{*}{ Statistics } & \multicolumn{3}{|c|}{ Verbal } & \multicolumn{4}{|c|}{ Figurative } \\
\hline & & FLU & FLEX & ORIG & FLU & FLEX & ORIG & ELAB \\
\hline \multirow{2}{*}{$\mathrm{ACC}$} & Mean $^{a}$ & 12.13 & 7.56 & 8.46 & 16.41 & 10.87 & 13.35 & 2.33 \\
\hline & $(S D)$ & $(0.89)$ & $(0.40)$ & (1.49) & $(0.54)$ & $(0.32)$ & $(0.89)$ & $(0.38)$ \\
\hline \multirow{2}{*}{ B_A } & Mean & 15.58 & 8.64 & 12.67 & 15.27 & 9.67 & 10.45 & 4.51 \\
\hline & $(S D)$ & $(1.06)$ & $(0.47)$ & $(1.77)$ & $(0.64)$ & $(0.38)$ & $(1.06)$ & $(0.45)$ \\
\hline DEP & $F^{b}$ & 5.66 & 2.42 & 0.36 & 2.45 & 4.77 & 3.03 & 10.97 \\
\hline effect & p-value & 0.02 & 0.12 & 0.549 & 0.122 & 0.032 & 0.086 & 0.0014 \\
\hline Covariate & $F^{c}$ & 21.19 & 13.77 & 55.16 & 77.5 & 43.79 & 17.9 & 16.55 \\
\hline effect & p-value & 0.0001 & 0.0004 & 0.0001 & 0.0001 & 0.0001 & 0.0001 & 0.0001 \\
\hline
\end{tabular}

Notes:

a The means of the two groups are $a d j \overline{Y_{1 a}}$. and adj $\overline{Y_{2 a} \bullet}$ respectively. Pretest scores, $Y_{2 b}$ and $Y_{1 b}$, are the covariates in the ANCOVA model.

b The $F$ statistic represents the DEP effect test.

c The $F$ statistic represents the covariate effect test.

Table 6. $2 \times 2$ MANOVA Results

\begin{tabular}{|c|c|c|c|}
\hline \multirow{3}{*}{ Source } & \multirow{3}{*}{ d.f. } & \multicolumn{2}{|c|}{ Wilks' $\lambda$} \\
\hline & & Verbal & Figurative \\
\hline & & p-value & p-value \\
\hline \multirow{2}{*}{ DEP } & \multirow{2}{*}{1} & $0.96^{* *}$ & $0.90^{* *}$ \\
\hline & & $(0.0482)$ & $(0.0011)$ \\
\hline \multirow{2}{*}{ PRETEST } & \multirow{2}{*}{1} & $0.94^{* *}$ & $0.92^{* *}$ \\
\hline & & $(0.0085)$ & $(0.0045)$ \\
\hline \multirow{2}{*}{ INTERACTION $\quad($ DEP $\times$ PRETEST $)$} & \multirow{2}{*}{1} & 0.99 & 0.97 \\
\hline & & $(0.5706)$ & $(0.1835)$ \\
\hline
\end{tabular}

Error

185

Notes:

DEP and PRETEST are the two main factors. DEP has two levels of treatment, ACC and BA, depicting accounting and business students, respectively.

PRETEST also has two levels of treatment, PRETEST $_{a}$ and PRETEST ${ }_{c}$, depicting the students who participated/ did not participate in the pretest.

INTERACTION: DEP $\times$ PRETEST equals the effect.

The superscripts asterisks ${ }^{* *}$ denotes statistical significance at the $5 \%$ level.

Table 6 reports the results of MANOVA to test the main effects of the DEP and PRETEST, and their interactive effect. The DEP factor has two levels of treatment, accounting and business students are depicted as $\mathrm{DEP}_{1}$ and $\mathrm{DEP}_{2}$, respectively. The PRETEST factor also has two treatment levels, students with a pretest and without a pretest, depicted as PRETEST ${ }_{a}$ and PRETEST ${ }_{c}$, respectively. First, we have to examine where the interactive effect between the DEP factor and the PRETEST factor is significant before we can state any claims about the test 
results of these two main effects. More specifically, if the interactive effect is significant, it will then be out of the question to draw any conclusions from the tests of the main effects. The test statistics (the Wilks' $\lambda \mathrm{s}$ ) for Verbal Creativity Scores and Figural Creativity Scores are 0.99 and 0.97, with the p-values 0.5706 and 0.1835, respectively. Both statistics are insignificant at a five percent confidence level. The insignificance of the interactive effect paves the way for us to further analyze the test results of the main effects. For the DEP factor, the Wilks' $\lambda \mathrm{s}$ for variables Verbal and Figurative are 0.96 and 0.90 with the p-values 0.0482 and 0.0011 , respectively. For the PRETEST factor, the Wilks' $\lambda$ s are 0.94 and 0.92 with the p-values 0.0085 and 0.0045 , respectively.

It is clearly evident to see that the complexity of the preliminary MANOVA results provide limited information to draw inferences about the impacts of the accounting curriculum and the pretest on the subjects. Following the suggestion of Borgen and Seling (1978), we employ the linear discriminant function (LDF) analyses proposed by Tatsuoka (1971) that takes into account the multivariate nature of MANOVA when these variables are correlated as shown in Table 7.

Table 7 presents the correlations among the creativity subscores. The correlations between individual variables are all significant at a five percent confidence level across the board except for the one between variable ELAB and ORIG (0.05 only).

Table 7. Correlations among Raw Creativity Subscores

\begin{tabular}{|c|c|c|c|c|c|c|c|c|}
\hline & & \multicolumn{3}{|c|}{ Verbal } & \multicolumn{4}{|c|}{ Figurative } \\
\hline & & FLU & FLEX & ORIG & FLU & FLEX & ORIG & ELAB \\
\hline \multirow{3}{*}{ Verbal } & FLU & 1.00 & & & & & & \\
\hline & FLEX & $0.84^{* *}$ & 1.00 & & & & & \\
\hline & ORIG & $0.58^{* *}$ & $0.43^{* *}$ & 1.00 & & & & \\
\hline \multirow{4}{*}{ Figurative } & FLU & $0.45^{* *}$ & $0.43^{* *}$ & $0.21^{* *}$ & 1.00 & & & \\
\hline & FLEX & $0.39^{* *}$ & $0.38^{* *}$ & $0.20^{* *}$ & $0.82^{* *}$ & 1.00 & & \\
\hline & ORIG & $0.44^{* *}$ & $0.39^{* *}$ & $0.28^{* *}$ & $0.76^{* *}$ & $0.62^{* *}$ & 1.00 & \\
\hline & ELAB & $0.22^{* *}$ & $0.25^{* *}$ & 0.05 & $0.38^{* *}$ & $0.33^{* *}$ & $0.30^{* *}$ & 1.00 \\
\hline
\end{tabular}

Notes:

FLU: fluency; FLEX: flexibility; ORIG: originality; ELAB: elaboration

The superscripts asterisks ${ }^{* *}$ denotes statistical significance at the $5 \%$ level.

The LDF analysis is a classical approach for the identification of underlying dimensions. This analysis maximizes the separation between groups on some categorical variables by finding the optimal linear combination of several continuous variables. It yields one or more uncorrelated linear combinations of dependent variables that maximize differences among the groups.

We derived two linear composites (hereafter CAN-Verbal and CAN-Figurative) from the discriminant analysis. The canonical structure of correlations between creativity scores and their LDFs is summarized in Table 8 . The canonical correlation between verbal creativity scores and the canonical vitiate, CAN-Verbal, is 0.21 . The canonical correlation between figurative creativity scores and the canonical vitiate, CAN-Figurative, is 0.31 ; both are significant at a one percent confidence level. The square of the correlation coefficient shows the variance explained by the canonical variant. The results indicate that both dimensions are significant for explaining the effect of the grouping variable. We then analyzed what made the two groups of students different according to these underlying creativity dimensions.

In Table 8, the Verbal_FLU has the highest factor loading (0.87), followed by Verbal_FLEX (0.73) on the CAN-Verbal dimension. Nevertheless, Verbal_ORIG only has an inconsequential loading (0.05). Alternatively, Figurative_ELAB has the highest negative factor loading on the CAN-Figurative dimension (-0.67), while the other 
three figurative scores only have slight loadings. Thus, we can treat these two underlying dimensions (CAN-Verbal and CAN-Figurative) as Verbal Creativity Index and Anti-Figurative Creativity Index.

Table 8. The Canonical Structure of Correlation Coefficients and Loadings between Subscores and LDF

\begin{tabular}{|c|c|c|c|c|c|c|c|}
\hline \multicolumn{4}{|c|}{ CAN-Verbal } & \multicolumn{4}{|c|}{ CAN-Figurative } \\
\hline \multicolumn{2}{|c|}{ Subscores } & \multirow{2}{*}{$\begin{array}{c}\text { Loading } \\
0.87\end{array}$} & \multirow[t]{2}{*}{$\begin{array}{l}\text { Canonical } \\
\text { correlation }\end{array}$} & \multicolumn{2}{|c|}{ Subscores } & \multirow{2}{*}{$\begin{array}{c}\text { Loading } \\
-0.14\end{array}$} & \multirow[t]{2}{*}{$\begin{array}{l}\text { Canonical } \\
\text { correlation }\end{array}$} \\
\hline \multirow{4}{*}{ Verbal } & FLU & & & \multirow{4}{*}{ Figurative } & FLU & & \\
\hline & FLEX & 0.73 & 0.21 & & FLEX & 0.13 & \multirow{3}{*}{0.31} \\
\hline & ORIG & 0.05 & & & ORIG & 0.12 & \\
\hline & & & & & ELAB & -0.67 & \\
\hline
\end{tabular}

Notes:

FLU: fluency; FLEX: flexibility; ORIG: originality; ELAB: elaboration.

CAN-Verbal: The first LDF of the verbal subscores as a canonical variable of verbal creativity.

CAN-Figurative: The first LDF of figurative subscores as a canonical variable of figurative creativity.

Figure 4 shows the group means of these two-dimensional coordinated systems. It indicates that the experimental group (ACC students) has a lower Verbal Creativity Index and a higher Anti-Figurative Creativity Index, which indicates less figurative creativity. In contrast, the control group (BA Students) has a higher Verbal Creativity Index and a lower Anti-Figurative Creativity Index. These results suggest that the accounting curriculum has not been effectively enhancing students' verbal and figurative creativity.

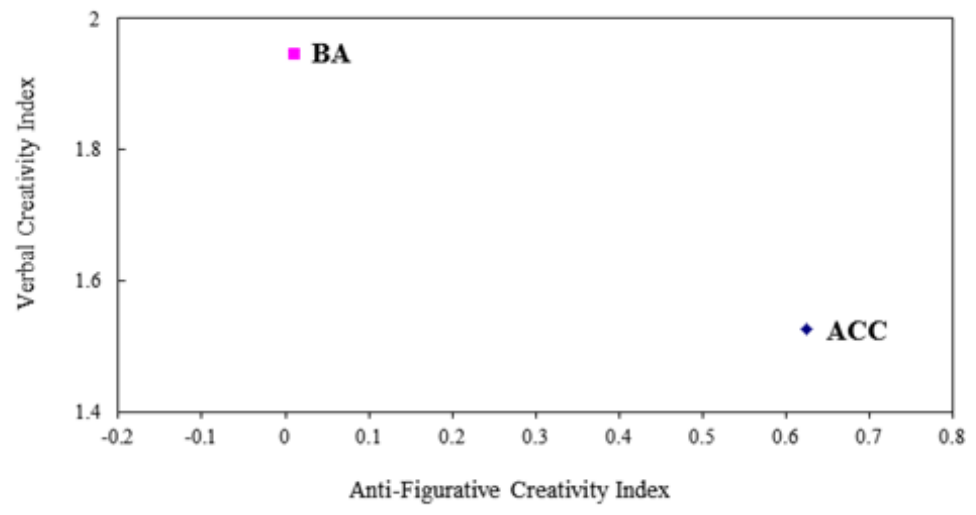

Figure 4. Group Means in Two Underlying Dimensions

For purposes of robustness, we employed an additive approach that has been extensively applied in prior studies as shown in Figure 3. First, we standardized the raw scores of the individual creativity variables. Secondly, we summed up the standardized scores to obtain a total standardized creativity score. Thirdly, a univariate $2 \times 2$ ANOVA on $\operatorname{DEP}\left(\mathrm{DEP}_{1}\right.$ vs. $\left.\mathrm{DEP}_{2}\right)$ and PRETEST $\left(\right.$ PRETEST $_{a}$ vs. PRETEST ${ }_{c}$ ); where $\mathrm{DEP}_{1}$ and $\mathrm{DEP}_{2}$ denote total standardized creativity scores for accounting (ACC) and business (BA) students, and PRETEST ${ }_{a}$ and PRETEST $_{c}$ denotes the subjects who participated in the pretest and the subjects who did not, respectively.

Panel A of Table 9 reports the ANOVA results. It indicates that there is no interaction between DEP and the PRETEST (the $F$-value is 1.39 with $p$-value 0.2398 ). We then proceeded to Step 2 to examine the main effect of the DEP treatment. The main effect of the total standardized creativity score is not significant, as the $F$-value is 1.3 with a $p$-value of 0.2556 . 
The insignificance of the main effect caused us to carry out Step 3, performing the ANCOVA to test the DEP treatment effect in $Y_{1 a}, Y_{2 a}$ with the pretest scores $Y_{1 b}, Y_{2 b}$ as covariates. Panel B shows that the ANCOVA for the total standardized creativity score is not significant at a five percent confidence level $(F$-value is 1.04 and $p$-value is 0.3108 ). We then proceeded to carry out Step 4, performing an independent sample t-test on the total standardized creativity score of $Y_{1 c}, Y_{2 c}$, which is the post-test-only groups (Panel C). The test statistic (using $\overline{Y_{1 c}}-\overline{Y_{2 c}}$ ) is also insignificant, (the $t$-value is 1.85 with a $p$-value of 0.067 ).

Table 9. Results of Additional Test Using Total Standardized Scores ${ }^{\text {a }}$

\begin{tabular}{|c|c|c|c|c|c|}
\hline \multicolumn{2}{|l|}{ Panel A: $2 \times 2$ ANOVA } & \multirow{3}{*}{$\begin{array}{c}d . f . \\
1\end{array}$} & \multirow{2}{*}{\multicolumn{3}{|c|}{$F \quad(p$-value $)$}} \\
\hline \multicolumn{2}{|l|}{ Source } & & & & \\
\hline \multicolumn{2}{|l|}{ INTERACTION $($ DEP $\times$ PRETEST) } & & \multicolumn{3}{|c|}{$1.39 \quad(\mathbf{0 . 2 3 9 8})($ Step 1 in Figure. 3) } \\
\hline \multicolumn{2}{|l|}{ DEP } & 1 & 1.30 & \multicolumn{2}{|c|}{$(\mathbf{0 . 2 5 5 6 )}($ Step 2 in Figure. 3$)$} \\
\hline \multicolumn{2}{|l|}{ PRETEST } & 1 & \multirow[t]{2}{*}{7.76} & \multicolumn{2}{|c|}{$(0.0059)$} \\
\hline \multicolumn{2}{|l|}{ Error } & 185 & & & \\
\hline \multicolumn{6}{|l|}{ Panel B: One way ANCOVA } \\
\hline \multicolumn{2}{|l|}{ Source } & d.f. & \multicolumn{3}{|c|}{$F \quad(p$-value $)$} \\
\hline \multicolumn{2}{|l|}{$\overline{\operatorname{DEP}}(X$ factor $)$} & 1 & \multirow{2}{*}{\multicolumn{2}{|c|}{$1.04 \quad(0.3108)$}} & (Step 3 in Figure. 3) \\
\hline \multicolumn{2}{|l|}{ Error } & \multicolumn{2}{|l|}{76} & & \\
\hline \multicolumn{6}{|l|}{ Panel C: $t$ test on $Y_{1 c}, Y_{2 c}$} \\
\hline Mean & $(S D)$ & \multicolumn{2}{|c|}{ d.f. } & $t$ & (p-value) \\
\hline 70.00 & $(32.1)$ & \multirow{2}{*}{\multicolumn{2}{|c|}{108}} & \multirow{2}{*}{1.85} & $(0.067)$ \\
\hline 60.00 & $(24.4)$ & & & & (Step 4 in Figure. 3) \\
\hline \multicolumn{6}{|c|}{ Panel D: Meta-analysis to combine ANCOVA result with $t$ test results } \\
\hline \multicolumn{3}{|c|}{$p$-value } & \multicolumn{3}{|c|}{$z$} \\
\hline ANCOVA & 0.3018 & & \multicolumn{3}{|c|}{$Z_{p 1}=1.02$} \\
\hline$t$ test & 0.067 & & \multicolumn{3}{|c|}{$z_{p 2}=1.81$} \\
\hline Meta-analysis & $0.0456 *$ & & \multicolumn{3}{|c|}{$Z_{\text {meta }}=\mathbf{2 . 0 0 1}{ }^{\mathrm{c}}($ Step 5 in Figure. 3$)$} \\
\hline
\end{tabular}

Notes:

a Total Standardized Score is the sum of 7 standardized creativity subscores.

b The same hypotheses are to test no DEP treatment effect.

c Stouffer's $Z_{\text {meta }}, Z_{\text {meta }}=\sum_{i} z_{p i} / \sqrt{k}$, here $k=2$.

The superscripts asterisks ${ }^{* *}$ denotes statistical significance at the $5 \%$ level.

Finally, we performed the final step using meta-analysis as suggested by Braver and Braver (1988). Meta-analysis is a set of statistical procedures for combining the results from several studies to see if there is an overall effect. In this study, we applied Stouffer's $Z$ (Stouffer et al., 1949) to combine the results of ANCOVA and the t-test. The null hypothesis can be assessed by a combined z-score. This is simply a weighted average of the number of standard deviations of the results deviated from chance, and its likelihood can be assessed using the standard statistical tables. The Stouffer's $Z \quad\left(Z_{\text {meta }}\right.$ ) can be computed according to the following formula:

$$
Z_{\text {meta }}=\sum_{i} z_{p i} / \sqrt{k}
$$

where $z_{p i}$ refers to the one-tailed $p$-value associated with the $i$ th statistical test and $k$ is the number of such tests.

Panel D indicates that the meta-analytic result is significant at a five percent confidence level, $\left(Z_{\text {meta }}=2.001\right.$ with a $p$-value of 0.0456). This suggests that the DEP factor has an effect on the total standardized creativity score. ACC 
students' creativity scores are less than BA students' after controlling the PRETEST effect. We thus conclude that although both accounting and business curriculums have their merits and drawbacks with respect to creative thinking, the accounting curriculum across the board has been less effective than the business curriculum in improving students' creativity.

\section{Conclusions}

A broad American Accounting Association sponsored research project from 2000 indicated that there exists an enormous gap between what is being taught in the accounting classroom and what is being practiced in the evolving global marketplace. After the Enron and WorldCom scandals, the Big-Four firms, the AAA, the AICPA, and the Institute of Management Accountants have all announced plans to team up with top universities to develop curriculum changes.

In order to cope with the concerns expressed by the accounting professionals, we employed the TTCT to investigate whether the accounting curriculum had a negative effect on students' verbal and figurative creativity. The four-group Solomon design was employed to assess the effect of the accounting curriculum on these two creativity indices. The experimental group consisted of accounting freshmen, while business majors served as the control group. To enhance the internal validity, both the senior accounting majors and business majors were also tested for control purposes.

We found that the accounting freshmen had higher verbal creativity pretest scores than the business administration (BA) majors, while the differences were not as obvious with respect to figurative creativity. The test scores were further analyzed with MANOVA and meta-analysis. The results show that four years later business administration majors improved significantly in both verbal and figurative creativity as seniors, while accounting majors were stagnant in developing these two mental capacities. In the end, the differences of both verbal and figurative creativity between BA majors and accounting majors were statistically significant. These results were consistent with the concerns expressed by accounting professionals regarding the fact that the accounting educational methods need an overhaul to face the challenges of the modern business environment. Stanley and Marsden (2012, p. 271) suggest that an "accounting education should be more about learning to locate, obtain and organize information; the ability to identify and solve unstructured problems in unfamiliar settings; and to exercise judgment based on comprehension of an unfocused set of facts".

\section{References}

Albrecht, W. S., \& Sack, R. J. (2000). Accounting education: Charting the course through a perilous future. Accounting Education Series 16. Sarasota, FL: American Accounting Association.

Almeida, L. S., Prieto, L. P., Ferrando, M., Oliveira, E., \& Ferrándiz, C. (2008). Torrance test of creative thinking: The question of its construct validity. Thinking Skills and Creativity, 3, 53-58. http://dx.doi.org/10.1016/j.tsc.2008.03.003

Amabile, T. M. (1998, September-October). How to kill creativity: Keep doing what you're doing. Or, if you want to spark innovation, rethink how you motivate, reward, and assign work to people. Harvard Business Review 76(5), 77-87.

Borgen, F. H., \& Seling, M. J. (1978). Use of discriminant analysis following MANOVA: Multivariate statistics for multivariate purposes. Journal of Applied Psychology, 63(6), 689-697. http://dx.doi.org/10.1037/0021-9010.63.6.689

Bougen, P. D. (1994). Joking apart: The serious side to the accounting stereotype. Accounting, Organizations, and Society, 19(3), 319-335. http://dx.doi.org/10.1016/0361-3682(94)90039-6

Bracht, G. H., \& Glass, G. V. (1968, November). The external validity of experiment. American Educational Research Journal, 5(4), 437-474. http://dx.doi.org/10.3102/00028312005004437

Braver, M. C., \& Braver, S. L. (1988). The statistical treatment of the Solomon four-group design: A meta-analytic approach. Psychological Bulletin, 104(1), 150-154. http://dx.doi.org/10.1037/0033-2909.104.1.150

Bryant, S. M., Stone, D., \& Wier, B. (2011). An exploration of accountants, accounting work, and creativity. Behavioral Research in Accounting, 23(1), 45-64. http://dx.doi.org/10.2308/bria.2011.23.1.45

Campbell, D. T., \& Stanley, J. C. (1963). Experimental and quasi-experimental designs for research. Chicago: Rand McNally. 
Carnegie, G. D., \& Napier, C. J. (2010). Traditional accountants and business professionals: Portraying the accounting profession after Enron. Accounting, Organization and Society, 35(3), 360-376. http://dx.doi.org/10.1016/j.aos.2009.09.002

Colangelo, N., \& Davis, G. A. (1997). Handbook of gifted education. Boston: Allyn and Bacon.

Csikszentmihalyi, M. (1996). Creativity: Flow and the psychology of discovery and invention. New York: HarperCollins.

Donelan, J. G., \& Reed, R. O. (1992). Characteristics of accounting programs: A survey of students' perceptions. Journal of Accounting Education, 10, 191-209. http://dx.doi.org/10.1016/0748-5751(92)90025-Z

Driver, M. (2001). Fostering creativity in business education: Developing creative classroom environments to provide students with critical workplace competencies. Journal of Education for Business, 77(1), 28-34. http://dx.doi.org/10.1080/08832320109599667

Evans, E., Burritt, R., \& Guthrie, J. (2010). Accounting Education at a Crossroad in 2010. The Institute of Chartered Accountants in Australia.

Frensch, P. A., \& Sternberg, R. J. (1989). Expertise and intelligent thinking: When is it worse to know better? In: R. J. Sternberg (Ed.), Advances in the psychology of human intelligence. New York: Lawrence Erlbaum Associates, Inc.

Gowthorpe, C., \& Amat, O. (2005). Creative Accounting: Some Ethical Issues of Macro- and Micro-Manipulation. Journal of Business Ethics, 57(1), 55-64. http://dx.doi.org/10.1007/s10551-004-3822-5

Guilford, J. P. (1967). Creativity: Yesterday, today and tomorrow. The Journal of Creative Behavior, 1(1), 3-14. http://dx.doi.org/10.1002/j.2162-6057.1967.tb00002.x

Huck, S. W., \& Sandler, H. M. (1973). A note on the Solomon 4-group design: Appropriate statistical analyses. The Journal of Experimental Education, 42(2), 54-55. http://dx.doi.org/10.1080/00220973.1973.11011460

Jennings, M. M. (2004). Incorporating ethics and professionalism into accounting education and research: A discussion of the voids and advocacy for training in seminal works in business ethics. Issues in Accounting Education, 19(1), 7-26. http://dx.doi.org/10.2308/iace.2004.19.1.7

Johnston, S. (1997). Examining the examiners: An analysis of examiners' reports on doctoral theses. Studies in Higher Education, 22(3), 333-347. http://dx.doi.org/10.1080/03075079712331380936

Jones, S. H., \& Davidson, R. A. (2007) Measuring the Problem-Solving Abilities of Accounting and Other Business Students: A Comparison and Evaluation of Three Methods. Accounting Education, 16(1), 65-79. http://dx.doi.org/10.1080/09639280600826034

Karr, S. S. (2002, March/April). Striving for excellence. Financial Executive, 69-71.

Kealey, B. T., Holland, J., \& Watson, M. (2005). Preliminary Evidence on the Association between Critical Thinking and Performance in Principles of Accounting. Issues in Accounting Education, 20(1), 33-49. http://dx.doi.org/10.2308/iace.2005.20.1.33

Kerlinger, F. N., \& Lee, H. B. (2000). Foundations of Behavioral Research. Florida: Harcourt College Publishers.

Kim, K. H. (2006). Can we trust creativity tests? A review of the Torrance Tests of Creative Thinking (TTCT). Creativity Research Journal, 18(1), 3-14. http://dx.doi.org/10.1207/s15326934crj1801_2

Kim, K. H. (2011). The creativity crisis: The decrease in creative thinking scores on the Torrance Tests of Creative Thinking. Creativity Research Journal, 23(4), 285-295. http://dx.doi.org/10.1080/10400419.2011.627805

Krumm, G., Lemos, V., \& Filippetti, V. A. (2014). Factor structure of the Torrance Tests of Creative Thinking figural form B in Spanish-speaking children: Measurement invariance across gender. Creativity Research Journal, 26(1), 72-81. http://dx.doi.org/10.1080/10400419.2013.843908

Lissitz, R. W., \& Willhoft J. L. (1985). A methodological study of the Torrance Tests of Creativity. Journal of Educational Measurement, 22(1), 1-11. http://dx.doi.org/10.1111/j.1745-3984.1985.tb01044.x

Lovitts, B. E. (2005). Being a good course-taker is not enough: A theoretical perspective on the transition to independent research. Studies in Higher Education, 30(2), 137-154. http://dx.doi.org/10.1080/03075070500043093 
Mullins, G., \& Kiley, M. (2002). 'It's a PhD, not a Nobel Prize': How experienced examiners assess research theses. Studies in Higher Education, 27(4), 369-386. http://dx.doi.org/10.1080/0307507022000011507

Nickerson, R. S. (1999). Enhancing Creativity. In: Sternberg, R. J. (ed.), Handbook of creativity. Cambridge: Cambridge University Press.

Policastro, E., \& Gardner, H. (1999). From case studies to robust generalizations: An approach to the study of creativity. In: R. J. Sternberg (Ed.), Handbook of creativity. Cambridge: Cambridge University Press.

Porter, L. W., \& McKibbin, L. E. (1998). Management education and development: Drift or thrust into the 21st century. New York: McGraw-Hill Book Company.

Schlee, R. P., \& Harich, K. R. (2014). Teaching creativity to business students: How well are we doing? Journal of Education for Business, 89, 133-141. http://dx.doi.org/10.1080/08832323.2013.781987

Shalley, C. E., Zhou, J., \& Oldham, G. R. (2004). The effects of personal and contextual characteristics on creativity: Where should we go from here? Journal of Management, 30(6), 933-958.

Simonton, D. K. (1984). Genius, creativity, and leadership. Cambridge, MA: Harvard University Press,

Solomon, R. L. (1949). An extension of control group design. Psychological Bulletin, 46, 137-150. http://dx.doi.org/10.1037/h0062958

Springer, C. W., \& Borthick, A. F. (2004). Business simulation to stage critical thinking in introductory accounting: Rationale, design and implementation. Issues in Accounting Education, 19(3), 227-304. http://dx.doi.org/10.2308/iace.2004.19.3.277

Stanley, T., \& Marsden, S. (2012). Problem-based learning: Does accounting education need it? Journal of Accounting Education, 30, 267-289. http://dx.doi.org/10.1016/j.jaccedu.2012.08.005

Sternberg, R. J. (1997). Thinking Styles. New York: Cambridge University Press.

Stouffer, S. A., Suchman, E. A., DeVinney, L. C., Star, S. A., \& Williams, R. M. (1949). The American soldier: Adjustment to army life. NJ: Princeton.

Tatsuoka, M. M. (1971). Multivariate Analysis: Techniques for educational and psychological research. New York: John Wiley \& Sons, Inc..

Thompson, F., \& Washington, H. L. (2015, March). Critical thinking skills and teaching accounting: A comparative study. Journal of Finance and Accountancy, 19, 1-8.

Tinkler, P., \& Jackson, C. (2000). Examining the doctorate: institutional policy and the $\mathrm{PhD}$ examination process in Britain. Studies in Higher Education, 25(2), 167-180. http://dx.doi.org/10.1080/713696136

Torrance, E. P. (1962). Guiding creative talent. Englewood Cliffs, NJ: Prentice-Hall.

Torrance, E. P. (1966). The Torrance Tests of Creative Thinking - Norms-Technical Manual Research Edition Verbal Tests, Forms A and B - Figural Tests, Forms A and B. Princeton NJ: Personnel Press.

Torrance, E. P. (1974). The Torrance Test of Creative Thinking: Technical-norms manual. Bensenville, IL: Scholastic Testing Service.

Wilks, S. S. (1932). Certain generalizations in the analysis of variance. Biometrika, 24, 471-494. http://dx.doi.org/10.2307/2331979

Winter, R., Griffiths, M., \& Green, K. (2000). The 'academic' qualities of practice: What are the criteria for a practiced-based PhD? Studies in Higher Education, 25(1), 25-37. http://dx.doi.org/10.1080/030750700115993

Wu, J. J., Chen, Y. F., Guo, G.T., Lin, W. W., Liu, C. H., \& Chen, Y. H. (1998). Creative thinking test and research manual. Taipei, Taiwan: Ministry of Education.

\section{Notes}

Note 1. The Institute of Chartered Accountants in Australia: Accounting Education at a Crossroad in 2010 is edited by Evans E, Burritt R, Guthrie J.

Note 2. Torrance (1966 \& 1974) defined creativity as a process of becoming sensitive to problems, deficiencies, gaps in knowledge, missing elements, disharmonies, and so on; identifying the difficulty; searching for solutions, making guesses, or formulating hypotheses about the deficiencies: testing and retesting these hypotheses and possibly modifying and retesting them; and finally communicating the results. 